\title{
Integrative Pedagogical Framework to Support Construction Students' Professional Skills and Engagement
}

\section{Mr. Piyush Pradhananga, Florida International University}

Piyush Pradhananga is a Ph.D. student in Civil and Environmental Engineering at Florida International University (FIU). Piyush holds a B.S. in Civil Engineering from Tribhuwan University (TU). Following his graduation in 2016, he joined a leading real estate corporation in Nepal as the site engineer working on a multi-million project. He later joined a research firm based in London where he worked as an Engineering Graduate Researcher. Piyush is currently a Graduate Research Assistant at the Moss School of Construction, Sustainability, and Infrastructure at FIU where he focuses on multidisciplinary research that harmonizes sustainability in construction. His other research interests include Sustainable Construction, Construction Safety, Engineering Education, Green Building, and Energy Efficiency Measures.

\section{Mr. MOHAMED ELZOMOR, Florida International University}

Dr. Mohamed ElZomor is an Assistant Professor at Florida International University (FIU), College of Engineering and Computing and teaches at the Moss School of Construction, Infrastructure and Sustainability. Dr. ElZomor completed his doctorate at Arizona State University (ASU), Ira A. Fulton Schools of Engineering. Prior to attending ASU, Dr. ElZomor received a master's of science degree in Architecture from University of Arizona, a master's degree in Engineering and a bachelor of science in Construction Engineering from American University in Cairo. Dr. ElZomor moved to FIU from State University of New York, where he was an Assistant Professor at the college of Environmental Science and Forestry. Mohamed's work focuses on Sustainability of the Built Environment, Engineering Education, Construction Engineering, Energy Efficiency Measures and Modeling, Project Management, and Infrastructure Resilience. Dr. ElZomor has extensive professional project management experience as well as a diverse cross-disciplinary academic knowledge. Mohamed, distinct expertise supports fostering interdisciplinary research in addition to embracing innovative pedagogical approaches in STEM education. Dr. ElZomor has been integrating innovative and novel educational paradigms in STEM education to support student engagement, retention, and diversity.

\section{Ms. Gabriella Santi}

Gabriella Santi grew up in Caracas, Venezuela, where she pursued her Bachelor's of Science in Civil Engineering at the Universidad Metropolitana. After graduating, she worked for two years in a construction company where she was involved in various residential and infrastructure projects. As her interests shifted towards construction management, she then moved to Miami, Florida to pursue a master's degree in the Construction Management program at Florida International University. During her Master's program, she worked as a Graduate Research Assistant at Moss School of Construction Management, researching various topics related to sustainability in third world countries, robotic implementation in the construction industry and aiding STEM majors to improve their professional skills.

\section{Dr. Arif Mohaimin Sadri, Florida International University}

Dr. Arif Mohaimin Sadri is an Assistant Professor in the Moss School of Construction, Infrastructure and Sustainability (MSCIS) at the Florida International University (FIU). Previously he was a Visiting Assistant Professor in the Department of Civil and Environmental Engineering at the Rose-Hulman Institute of Technology and an Adjunct Professor in the Civil Engineering Dept. at the Valparaiso University. Dr. Sadri received his doctoral training from the Lyles School of Civil Engineering at Purdue University with a solid background in Civil Engineering (Transportation), Network Science, and Social Science. Dr. Sadri specializes in resilience engineering, evacuation modeling, shared mobility, social influence modeling, machine learning, agent-based modeling, and network modeling. Dr. Sadri's research focuses on the critical interdependence between social and infrastructure networks and integrates human proactive decision-making components into the civil infrastructure management challenges. Dr. Sadri develops human-centered and network-driven techniques that complement to the science of infrastructure resilience and sustainability. 


\title{
Integrative Pedagogical Framework to Support Construction Students' Professional Skills and Engagement
}

\begin{abstract}
Competent Construction Management (CM) graduates require an educational paradigm that go beyond conventional approaches, to align with the evolving workforce demands. This is especially true for underrepresented minority CM students, who must overcome additional barriers to succeed. To date, STEM students in general are offered conventional engineering education that depend on ineffective techniques, tiring introductory courses, and timeworn pedagogies. Research studies indicate that a shift to innovative pedagogical techniques such as problem-based learning (PBL), flipped classrooms and vertical integration are recommended to engage learners as well as actively develop their professional skills. This research implemented a pilot integrative learning approach, which couples PBL and vertical integration to successfully prepare minority CM students to thrive in their careers. Through this approach, three courses with different educational levels and instructional forms were connected by developing a shared project that addressed genuine and current construction issues. This research initiative targeted 48 minority CM students at a minority-serving institution and were evaluated in terms of selfreported professional skills. A pre and post-course survey tracked their progress throughout the semester which is analyzed through paired t-test and graphically represented with box plots with line plots. The results of the study show that this approach has a significant positive impact on CM students, especially minorities, in terms of improving their professional skills, implicitly supporting their retention and paving for successful careers. The findings of the study contribute to the engineering education body of knowledge on the integrative learning approach and its effectiveness in improving minority students' overall performance and professional skills.
\end{abstract}

\section{Introduction and Background}

Construction management $(\mathrm{CM})$ is one of the growing careers in the booming US construction industry since there is an increasing demand for professionals to manage construction activities [1].The growth in demand is projected to increase by 10 percent from 2018 to 2028 , with the anticipated increase in construction activities over the coming decade [2]. However, due to the growing complexity of construction processes and the dynamic nature of the construction industry, there is a necessity for an innovative pedagogy that could help CM students familiarize themselves with real-construction site issues and engage in problem-solving skills. Conventional construction pedagogical methods put students in a passive role, especially when solving predictable construction problems with simplistic and anticipated solutions [3]. In general, most STEM coursework are heavily skewed towards writing deliverables, which ultimately hinders active engagement [4]. Thus, a paradigm shift in pedagogical methods such as integrative learning is required in $\mathrm{CM}$ programs to prepare minority $\mathrm{CM}$ students with the skills and knowledge to interface with the unstructured challenging environment of the construction industry. An integrative learning pedagogical methodology is a potential innovative method that has been found to be effective in other disciplines, such as the medical field; specifically to prepare students through inter and intra-disciplinary curriculum, which acts as a nexus to develop 
skills with real-world implications [5]. This approach is student-centered, and it fosters integrative learning and performance-based assessment; thus, it shows a significant potential to improve CM pedagogy and develop students' soft skills [6]. A similar vertically integrative problem-based learning framework was implemented between undergraduate CM students and graduate civil engineering students at Arizona State University in a face to face environment; through such learning framework, students' soft skills improved, as well as their intent to pursue an advanced degree and to stay in the major [7]. Such an integrative approach has also been found to be effective in other studies improving collaborative, interactional competence and leadership and management skills [8]. All previous initiatives are offered in face-to face courses despite most of the current education environment incorporates different instructional forms, online/face-to-face and Hybrid and the effectiveness of such innovative pedagogical methodology has not yet been scrutinized till date in these instructional forms.

The vertical integration implementation embraced a problem-based learning (PBL) approach. PBL was initially developed by Postman and Weingartner [9]; PBL was an unconventional mode of teaching as it encouraged the development of complex questions as well as the integration of open-ended problems [10]. ElZomor [6] and Prieto [11] explains that PBL represents flexible and effective strategies that, based on what the students do, can improve the quality of their university learning in many different aspects. Overall, research indicates PBL is an appropriate strategy for teaching students to engage in complex problem solving, and indeed may be one of the most effective methods for doing so [12], [13]. PBL is not only a method that encourages critical thinking and exposes students to real world problems, but more importantly, supports students' developing their own learning techniques, fosters collaboration with others, and promotes research [14].

Successful implementation of the integrative learning approach in the nursing field indicated that students exposed to such pedagogies were able to make proactive decisions in real patient scenarios and utilize their profound knowledge for the understanding of patient conditions [15]. Another study explored the effectiveness of a problem-based pedagogy for comparing the confidence improvements in leadership skills [16]. In an online environment, collaborative teamwork through an integrative approach provided an experiential learning experience exposing students to the professional world [17]. However, it has been observed that students experience anxiety during the initial phases of the problem-based learning process. So, in order to develop leadership skills, learning from initially felt anxiety was found to be significant for effective implementation [18]. A project-based learning approach was also assessed with crowd signals and the results showed a comparison between the rate of failure occurrence in student projects with that of industry projects [19]. Furthermore, a study highlighted that an integrative learning module influenced freshman engineering students' perceptions of engineers after the integration of different interdisciplinary courses, such as social sciences, humanities and engineering. Ultimately, this approach fostered effective critical thinking abilities to solve complex engineering issues and helped students comprehend the true applications of STEM concepts [20]. That said, many minority CM students can benefit from this alternative learning pedagogy, to successfully create nurturing educational environments. Engineering and CM curricula could 
integrate this approach and/or explore new pedagogies that encourage the development of minority students' professional skills [14], [15], [16].

Thus, this paper presents an integrative learning approach implemented within three CM courses at a minority-serving institution. These courses involved minority students from different educational backgrounds, academic levels and were connected through a common shared project showcasing real-life construction issues. The integrative learning framework facilitates the stimulation of intellectual curiosity and critical thinking to increase engagement in students during their learning experience [21]. The authors piloted the framework in the Spring 2019 semester, and lessons learned resulted in a more refined and restructured approach. Thus, this study addresses two research questions: (1) Is an integrative learning framework effective based on self-reported student ratings and statistical significance? and; (2) Does implementing the integrative framework result in improvements to minority CM students' performance and professional skills? The subsequent sections present the methodological implementation of the integrative learning approach, then reports the results and discusses the analysis.

\section{Methodology}

This section presents the implementation of an integrative framework consisting of a common shared construction project. The framework facilitated a cross-course collaboration between three different instructional course forms, BCN 2210, BCN 4570/BCN 5585, and BCN 4431. The integration was based on a construction project that required input and expertise from the students in the different courses. Each group consisted of 3-5 students from each of the courses and they were encouraged to use any of the common workspaces around the campus and any online discussion venues. In particular, this framework emphasized verbal and written communication through face to face interaction, online discussion, or online virtual meetings, which was previously effectively implemented in STEM courses. Regarding face-to-face interactions between student bodies: first was the kickoff meeting, and then the students conducted a face-to-face interaction for solving common problems. The kickoff meeting was conducted to initiate collaborations and facilitation of effective communication between student populations. The deliverables of the integrative project were based on lectures, class discussions, course readings, and required additional independent research. To promote better coordination and success in the courses' project, the instructors shared all students' emails and they were required to attach a group picture during each face-to-face deliverable.

BCN 2210 is a required undergraduate construction management course taught each semester. It provides students with knowledge related to identification and comprehension about the most common building materials and construction methodologies. BCN 4570 / BCN 5585 are construction management courses offered each semester to undergraduate and graduate students. These two courses' learning objectives mainly include explaining the concepts and techniques of sustainable construction and profoundly reviewing sustainable construction materials and techniques. BCN 4431 is an introductory course to undergraduate students that helps students develop knowledge on material properties, design of different structures. The student body for 
this study consists of 48 students in which $46 \%$ of students are seniors, while $31 \%$ are juniors, $21 \%$ are sophomores, $1 \%$ are freshmen and $1 \%$ are in high school. Student progress and the framework's impact was assessed through pre and post-course evaluations. Students were asked to create one unique unanimous personal identification code (last four letters of the name of the city where you were born + last four digits of students' phone numbers) to match their responses. Figure 1 illustrates the different goals of the integrative framework, metrics, instruments used to evaluate each objective and the type of measurement each metric represents.

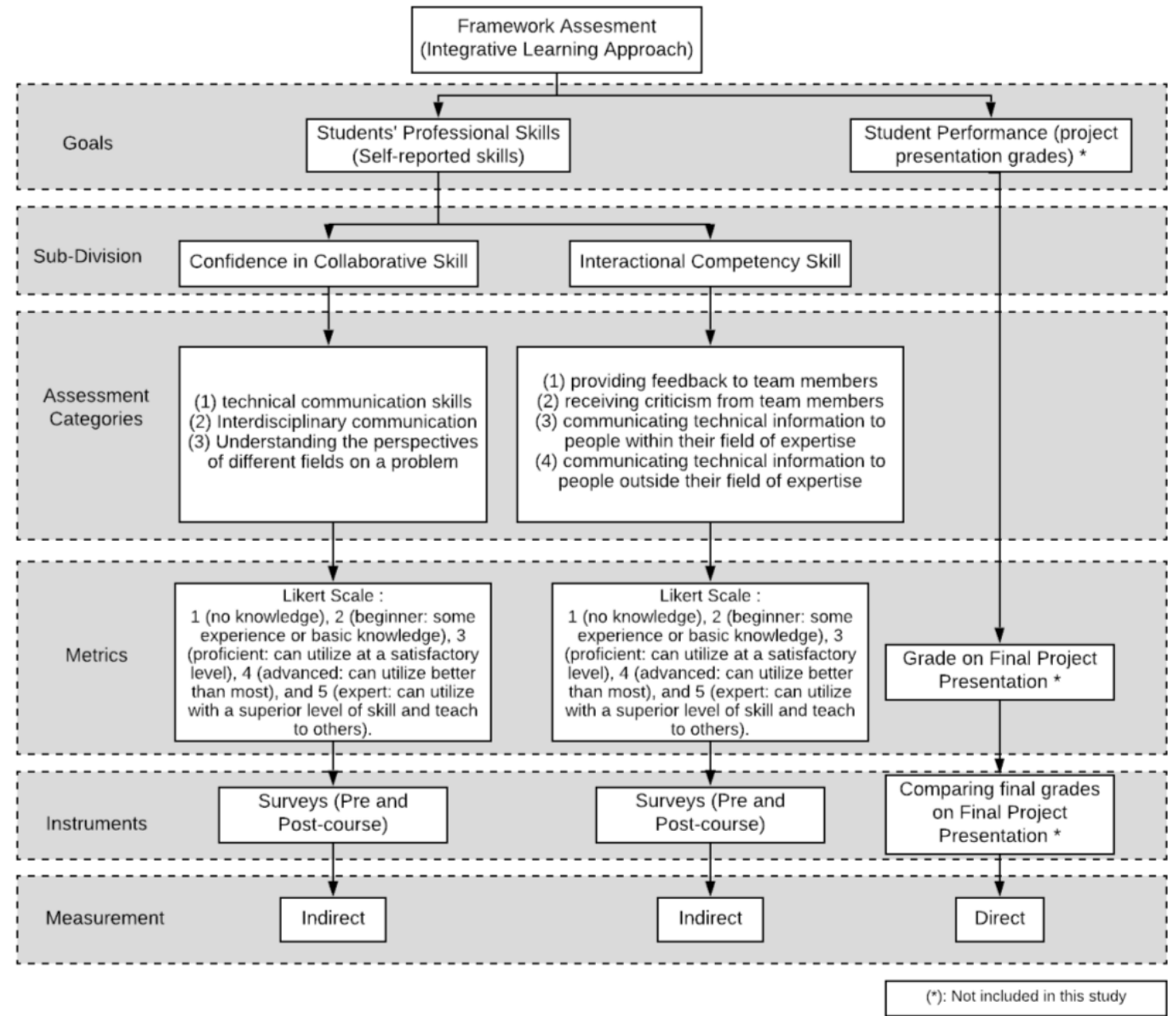

Figure 1: Framework Assessment Method

The authors evaluated the self-reported skills, which includes interactional competency skills and confidence in collaborative skills. For better comprehension of the students' professional skills, box plots with line plots were made using R-studio, which provided an understanding of how the comparable results are spread out. The pre- and post-course surveys in this study are also used to evaluate the effectiveness of integrative learning approach in CM courses. The responses from pre- and post-course surveys were matched and compared using paired t-tests in SPSS. A paired $\mathrm{t}$-test is a parametric test in which assumptions are made about the parameters of the distributed population from which a sample has been drawn. This analysis focuses on determining whether 
the mean difference between two sets of observations; for example, individual scores in each of the survey sets, is equal to zero or not. As such, for paired t-test in SPSS, a confidence interval of $95 \%$ is set for the analysis.

\section{Results and Discussion}

This section presents the results of this study and addresses the two research questions. To address research question one, concerning the effectiveness of an integrative learning pedagogy on the overall student performance, the authors compared the students' self-ratings during the beginning and end of the Spring 2019 semester. To address research question two, concerning students' professional skills and confidence, the authors' assessment included questionnaire surveys that asked students to report their current skill level and confidence. The minority students targeted through this research are registered students at a minority-serving institution and consisted of $21 \%$ female, and $79 \%$ male, with $11 \%$ of them being veterans and consisting of multiple races, such as Hispanic, African American, etc. as shown in Figure 2.

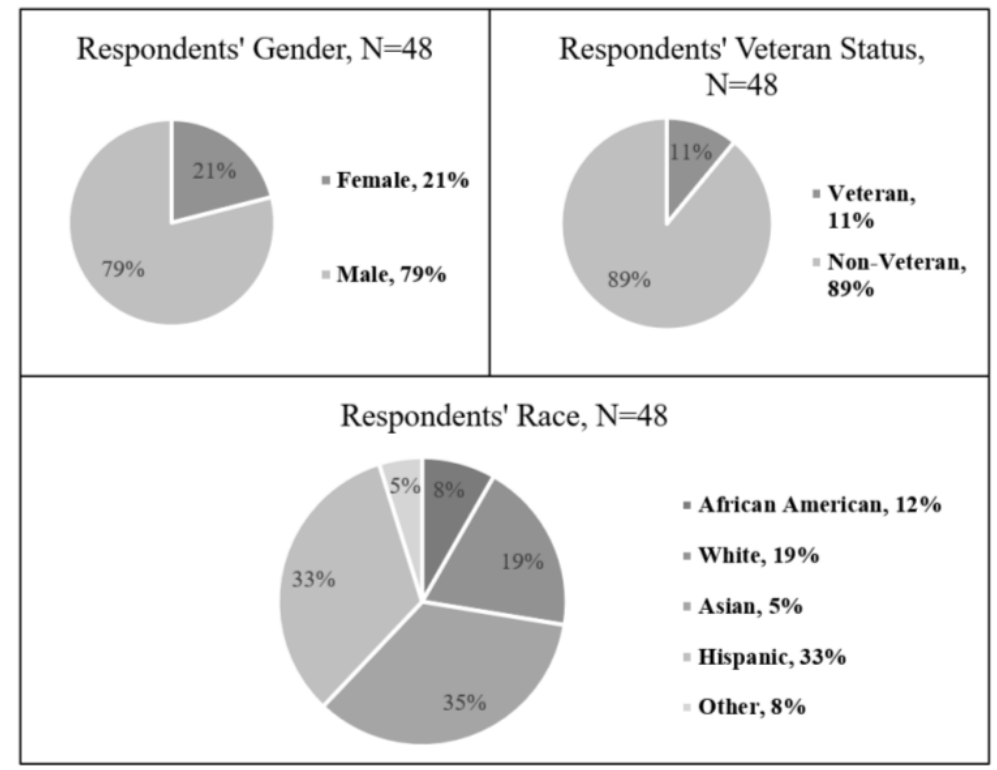

Figure 2. Respondents' Socio Demographics

\section{Effectiveness of Integrative learning framework}

To identify the effectiveness of integrative learning framework in achieving the overall project deliverables, a paired t-test was conducted using the pre- and post-course survey data. From the assessment of all the three-course (Table 1), it could be observed that students, in general, have found an integrative learning framework to be effective for learning and professional development, as well as in supporting overall class-deliverables. 
Table 1: Paired T-test analysis for effectiveness of integrative learning approach

\begin{tabular}{|c|c|c|c|c|c|}
\hline S.N. & Variables & $\begin{array}{c}\text { Absolute } \\
\text { Mean } \\
\text { Difference }\end{array}$ & $\mathrm{t}$ & $\begin{array}{c}\text { Degree } \\
\text { of } \\
\text { Freedom }\end{array}$ & $\begin{array}{c}\text { P- } \\
\text { Value }\end{array}$ \\
\hline 1. & $\begin{array}{c}\text { The integrative learning approach has helped me to be more engaged with } \\
\text { the program }\end{array}$ & -1.3 & -6.331 & 47 & $<0.05$ \\
\hline 2. & $\begin{array}{l}\text { The integration between courses has led to mentoring or supporting other } \\
\text { students }\end{array}$ & -1.354 & -8.105 & 47 & $<0.05$ \\
\hline 3. & $\begin{array}{l}\text { I prefer working in groups especially when I work with other peers, I } \\
\text { perform than when I work alone }\end{array}$ & -1.188 & -6.587 & 47 & $<0.05$ \\
\hline 4. & I was excited to participate in Cooperative/Active learning activities & -1.46 & -8.284 & 47 & $<0.05$ \\
\hline 5. & When I work with other students, I perform better than when I work alone & -1.229 & -8.385 & 47 & $<0.05$ \\
\hline 6. & $\begin{array}{c}\text { Cooperative/Active learning can improve my attitude towards working in } \\
\text { team }\end{array}$ & -0.854 & -4.921 & 47 & $<0.05$ \\
\hline 7. & $\begin{array}{c}\text { Cooperative/Active learning enhances good working relationships among } \\
\text { students in other courses }\end{array}$ & -0.729 & -4.924 & 47 & $<0.05$ \\
\hline 8. & Cooperative/Active learning enhances engagement and class participation & -0.792 & -5.322 & 47 & $<0.05$ \\
\hline 9. & Creativity is facilitated in the group setting & -0.917 & -6.057 & 47 & $<0.05$ \\
\hline 10. & Group activities make the learning experience easier & -1.00 & -6.132 & 47 & $<0.05$ \\
\hline 11. & $\begin{array}{l}\text { Through the vertical integration, I learn to work with students who are } \\
\text { different from me }\end{array}$ & -1.188 & -5.839 & 47 & $<0.05$ \\
\hline 12. & My work is better organized when I am in a group & -1.6 & -10.62 & 47 & $<0.05$ \\
\hline 13. & I prefer that my teachers use more group activities/assignments & -1.52 & -7.978 & 47 & $<0.05$ \\
\hline 14. & $\begin{array}{c}\begin{array}{c}\text { I enjoy working with different students especially experienced students in } \\
\text { other courses }\end{array} \\
\end{array}$ & -1.35 & -9.008 & 47 & $<0.05$ \\
\hline 15. & $\begin{array}{c}\text { Collaborating across online, face-to-face was challenging, but it resembles } \\
\text { the real working environments }\end{array}$ & -1.146 & -6.328 & 47 & $<0.05$ \\
\hline
\end{tabular}

It can be concluded that the P-value is less than 0.05 for all the variables indicating there is a significant difference in the means of the pre- and post-course results. The absolute mean difference for each of the variables has a negative sign which means that the overall self-reported rating positively increased at the end of the semester, as observed in the post-course survey. The obtained result of the analysis indicates that the integrative learning framework increased: (1) engagement; (2) effective mentoring; (3) interest in teamwork; (4) participation in Cooperative/Active learning activities; (5) positive attitude towards working in team; (6) better performance in group work; (7) good working relationships among other students in other courses; (8) engagement and class participation; (9) creativity in group setting; (10) enhancement in learning experience; (11) collaboration with students who are different; (12) organization; (13) group activities/assignments; (14) interest to work with experienced students and; (15) positive experience during collaboration in different instructional forms.

Additionally, the effectiveness of the integrative learning framework was also represented with box plots to understand its success in supporting retention within the program, enhancing collaborations and understanding throughout the program, and enhancing minority students' professional/academic career based on the self-ratings. The authors assessed the effectiveness of the integrative learning framework based on a five-point Likert scale from 1 (Not at all effective) to 5 (Extremely effective). The median value based on students' self-evaluation (shown as a thicker line in Figure 3) indicates that at the start of the semester, minority students rated retention in the program, understanding of program and professional/academic career as moderately effective (see Figure 3). While at the end of the course, the minority students rated the approach as very effective for program understanding and impact on their 
professional/academic career. While some students reported a reduction in the effectiveness of retention in the program, program understanding, and impact on professional/academic career, the majority of the students indicated a one-level increase over the semester in these same areas. These results are possibly due to ease of communication and increased collaboration between students. Whereas no change was observed for retention in program.

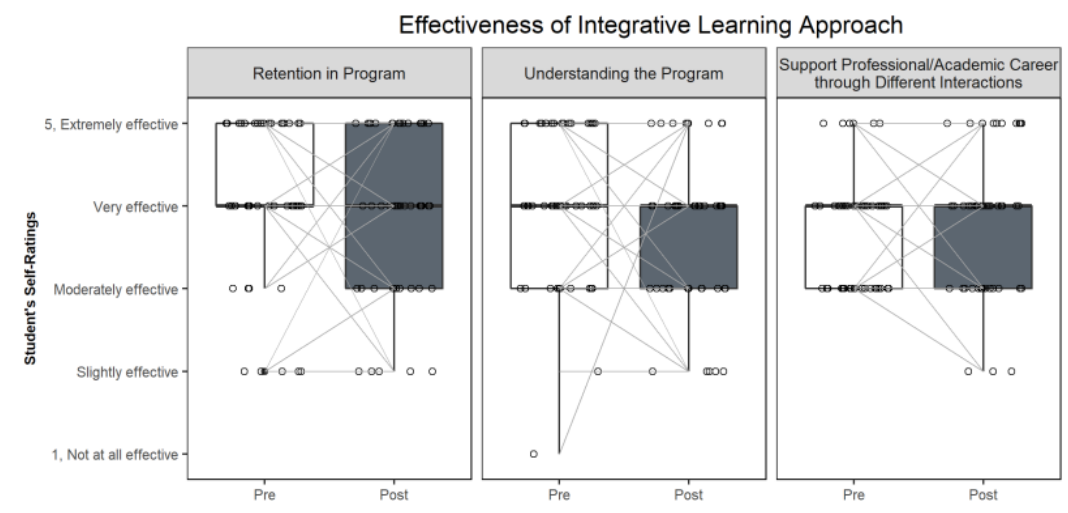

Figure 3: Effectiveness of integrative learning framework based on students' self-ratings ( $N=48$ )

The authors focused on three Interactional Competence (IC) skills which include: (1) technical communication skills (i.e., talking with someone from within your course); (2) Interdisciplinary communication (i.e., talking about technical details with someone from outside of your course) and; (3) Understanding the perspectives of different fields on a problem as shown in Fig. 4. Minority students were assessed for their skills in IC on the five-point scale: 1 (no knowledge), 2 (beginner: some experience or basic knowledge), 3 (proficient: can utilize at a satisfactory level), 4 (advanced: can utilize better than most), and 5 (expert: can utilize with a superior level of skill and teach to others). The survey results indicated that students assessed more growth for themselves and reported a gain in confidence in technical communication skills. The median value based on students' self-reported responses (shown as a thicker line in Figure 4) indicates that at the start and end of the course, the median student rated herself/himself as an advanced in technical communication skills. However, some students reported a reduction in skill level for technical communication, interdisciplinary communication and understanding the perspectives of different fields on a problem at the start and end of the course. These minority students might require additional learning pedagogies that successfully foster their professional growth.

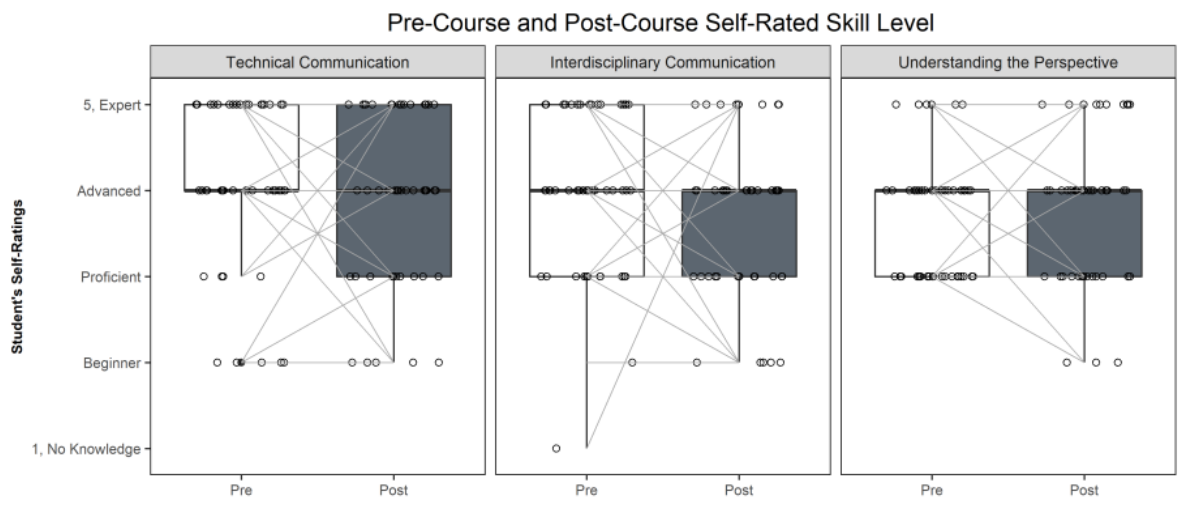

Figure 4: Pre and Post-course self-rated current skill level $(\mathrm{N}=48)$ 
Confidence in Collaborative (CC) skills developed by minority students through the framework include: (1) providing feedback to team members, (2) receiving criticism from team members, (3) communicating technical information to people within their field of expertise and, (4) communicating technical information to people outside their field of expertise (technical interdisciplinary communication). This was assessed based on a five-point Likert scale from 1 (Not at all confident they could do this) to 5 (extremely confident they could be highly successful and could teach others to be successful). Students' self-reported confidence in collaborative skills at the start and end of the course. These results are represented in the form of box plots with line plots (see Figure 5). Although some students did not show improvement, results indicate that a significant percent of the students increased their confidence in collaboration skills throughout the course. Moreover, mean and median differences show that students who were moderately confident in a pre-course survey developed more confidence in their collaborative skills during the post-course survey.

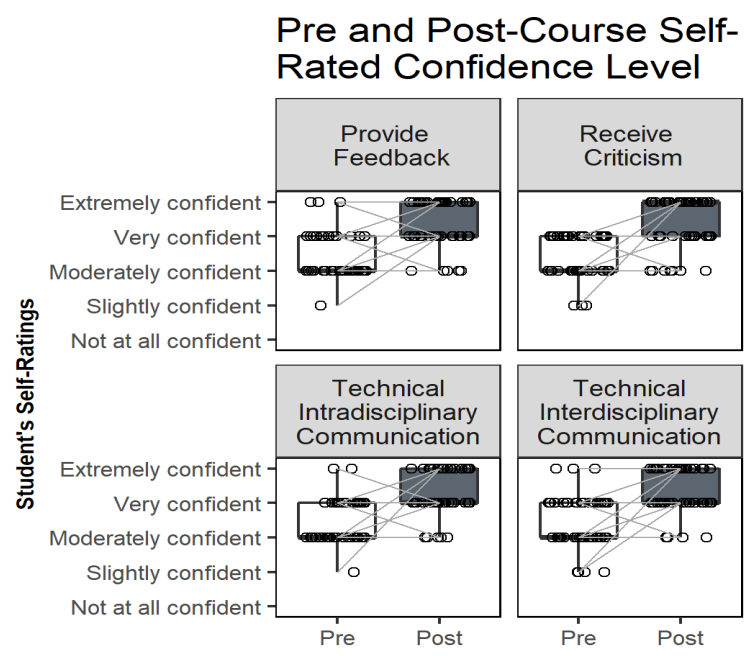

Figure 5: Pre and Post-course self-rated confidence level $(\mathrm{N}=48)$

Minority students' grades in all three classes BCN 2210, BCN 4570/BCN 5585, and BCN 4431 also improved at the end of the Spring 2019 semester. The authors believe this improvement is due to the integrative knowledge gained through different activities in the framework and several students were able to enhance their learning experience. All of these improvements were reflected in the final project report of the integrative learning course and it indicates that such a framework is effective not only in develop professional skills but also in enhancing their overall academic performance. Moreover, these students provided their feedback into the implementation of the learning approach. Where $60 \%$ stated they believe this approach has positively affected their professional growth, as shown in Table 2. Overall, this study indicates it is successful in fostering minority students' professional growth and promotes nurturing educational environments. 
Table 2. Sample of Students' Feedback about the Learning Approach

I think it is a better experience for younger students. Ex: sophomore students get to learn more from the juniors and seniors, than the seniors from sophomores.

I think working with others and collaborating with the team is one way to gain experience. In the real world, our industry is a people's person job.

Useful because it gives and preview of what to expect in the real-world environment My experience in this course will influence my career goals as it has introduced a change in my way of thinking towards a more sustainable way.

The experience I have gained through participating in this group project has given me the necessary practice in collaborating on projects with people that I don't always have the chance to see in person

Very unique especially due to working with other people

\section{Limitation}

The authors acknowledge that there are some limitations to the proposed integrative learning framework, including: the skill level reported by students may be over or underestimated based on students' actual skill levels, thus the results may not be identical if the framework is implemented at other institutions. Another limitation may be that the effectiveness of the framework at promoting retention in CM programs may vary between institutions and settings.

\section{Conclusion}

This study evaluated the effectiveness of an integrative learning framework in improving the skills of minority CM students in different construction management courses by using pre-and post-course surveys. A paired t-test and box plot showed the effectiveness of the integrative approach in increasing retention in the courses, understanding the program, and impact on minority students' professional/academic career. Indeed, the integrative learning approach increased engagement, participation in cooperative/active learning activities and positive attitude towards working in teams. It also fostered effective mentoring, interest in teamwork and better performance in group work. Since good working relationships in a group project is significant, the integrative framework not only helped to achieve this but also improved engagement and class participation. It was also observed that minority students became more creative in group settings and there was an enhancement in the learning experience. Additionally, the students from all three courses improved their grades, which could be associated with exposure to more engaging tasks in the integrative learning framework. Overall, $60 \%$ of the minority students expressed their belief that this activity had significant positive impact on their professional development. Therefore, this study validates the positive impact of the integrative learning approach on minority student performance. Future research should collect more comprehensive data and capture the performance of minority construction managers in the industry to quantify the level of influence in construction learning in a versatile environment beyond the semester.

\section{References}

[1] Wei, M., Patadia, S., Kammen, D. M., "Putting renewables and energy efficiency to work: How many jobs can the clean energy industry generate in the US?," Energy Policy, vol. 38, no. 2, pp. 919-931, 2010. 
[2] H. Duan, Miller, Travis R., Liu, Gang, Tam, Vivian W.Y., "Construction debris becomes growing concern of growing cities," Waste Management, vol. 83, pp. 1-5, Jan 2019.

[3] A. Morello, Issa, R. R. A., Franz, B., "Exploratory Study of Recruitment and Retention of Women in the Construction Industry," American Society of Civil Engineer, 2018.

[4] J. Jung, Caffarella, R. S., "Advancing Cultural Knowledge: Experiential Learning International Graduate Study Training Programs in the Health and STEM Disciplines," in Adult Education Research Conference, 2010.

[5] C. A. Webster, D. F. Stodden, R. L. Carson, C. Egan, and D. Nesbitt, "Integrative Public Health-Aligned Physical Education and Implications for the Professional Preparation of Future Teachers and Teacher Educators/Researchers in the Field," Quest, vol. 68, no. 4, pp. 457-474, 2016.

[6] L. J. Hinchliffe and M. A. Wong, "From Services-Centered to Student-Centered: A "Wellness Wheel" Approach to Developing the Library as an Integrative Learning Commons," College \& Undergraduate Libraries, vol. 17, no. 2-3, pp. 213-224, 2010.

[7] M. ElZomor, Mann, C., Doten-Snitker, K., Parrish, K., Chester, M., "Leveraging Vertically Integrated Courses and Problem-Based Learning to Improve Students' Performance and Skills," American Society of Civil Engineer, 2018.

[8] J. N. Ziyatdinova, Osipov, P. N., "Integrative Approach to Intercultural Competence Development in Engineering Education," IEEE, 2012.

[9] N. Postman and C. Weingartner, "Teachingas a subversive activity," New York: A Delta Book, 1969.

[10] E. Forcael, V. González, F. Orozco, A. Opazo, Á. Suazo, and P. Aránguiz, "Application of Problem-Based Learning to Teaching the Critical Path Method," Journal of Professional Issues in Engineering Education and Practice, vol. 141, no. 3, 2015.

[11] L. Prieto, "Active learning in the college classroom: A case study of problem-based learning.," (in Spanish), Miscelánea Comillas: Revista de Ciencias Humanas y Sociales (Spanish), no. 64(124), pp. 173-196, 2006.

[12] A. Shepherd, Cosgriff, Bryna, , "Problem-Based Learning: A Bridge between Planning Education and Planning Practice," Journal of Planning Education and Research, 1998.

[13] B. Tomkinson, R. Tomkinson, H. Dobson, and C. Engel, "Education for sustainable development - an inter-disciplinary pilot module for undergraduate engineers and scientists," International Journal of Sustainable Engineering, vol. 1, no. 1, pp. 69-76, 2008.

[14] N. Capon and D. Kuhn, "What's So Good About Problem-Based Learning?," Cognition and Instruction, vol. 22, no. 1, pp. 61-79, 2004.

[15] S. Murphy, I. Hartigan, N. Walshe, A. V. Flynn, and S. O'Brien, "Merging Problem-Based Learning and Simulation as an Innovative Pedagogy in Nurse Education," Clinical Simulation in Nursing, vol. 7, no. 4, pp. e141-e148, 2011.

[16] K. S. Scott, "An Integrative Framework for Problem-Based Learning and Action Learning," Human Resource Development Review, vol. 16, no. 1, pp. 3-34, 2017.

[17] C. McLoughlin, "Computer supported teamwork: An integrative approach to evaluating cooperative learning in an online environment," Australian Journal of Educational Technology, 2002.

[18] W. H. Newell, "The promise of Integrative Learning " in Reinventing Ourselves: Interdisciplinary Education, Collaborative Learning, and Experimentation in Higher Education, J. M. Barbara Leigh Smith, Ed., 1999.

[19] K. M. G. Georgalis, "Assessment of Project-Based Learning Courses Using Crowd Signals," in ASEE, 2019.

[20] K. P. Singer, Foutz, T., Navarro, M., Thompson, S., "Investigating The Extent That An Integrative Learning Module Broadens The Perception Of First-Year Students About The Engineering Profession," American Journal of Engineering Education, 2015.

[21] K. Becker, Park, K., "Effects of integrative approaches among science, technology, engineering, and mathematics (STEM) subjects on students' learning: A preliminary meta-analysis," Journal of STEM Education, 2011. 